Chapman University

Chapman University Digital Commons

Pharmacy Faculty Articles and Research

School of Pharmacy

2012

\title{
Synthesis and Anti-HIV Activities of Symmetrical Dicarboxylate Esters of Dinucleoside Reverse Transcriptase Inhibitors
}

Hitesh K.Agarwal

University of Rhode Island

Karen W. Buckheit

ImQuest BioSci Inc

Robert W. Buckheit Jr.

ImQuest BioSci Inc

Keykavous Parang

Chapman University, parang@chapman.edu

Follow this and additional works at: http://digitalcommons.chapman.edu/pharmacy_articles

Part of the Immune System Diseases Commons, and the Medical Biochemistry Commons

\section{Recommended Citation}

Agarwal, H. K., Buckheit, K. W., Buckheit, R. W. Jr, Parang, K. Synthesis and anti-HIV activities of symmetrical dicarboxylate esters of dinucleoside reverse transcriptase inhibitors. Bioorg. Med. Chem. Lett. (2012) 22, 5451-5454.

DOI:10.1016/j.bmcl.2012.07.037 


\title{
Synthesis and Anti-HIV Activities of Symmetrical Dicarboxylate Esters of Dinucleoside Reverse Transcriptase Inhibitors
}

\begin{abstract}
Comments
NOTICE: this is the author's version of a work that was accepted for publication in Bioorganic \& Medicinal Chemistry Letters. Changes resulting from the publishing process, such as peer review, editing, corrections, structural formatting, and other quality control mechanisms may not be reflected in this document. Changes may have been made to this work since it was submitted for publication. A definitive version was subsequently published in Bioorganic \& Medicinal Chemistry Letters, volume 22, in 2012. DOI: 10.1016/j.bmcl.2012.07.037
\end{abstract}

\section{Copyright}

Elsevier 


\title{
Synthesis and anti-HIV activities of symmetrical dicarboxylate esters of dinucleoside reverse transcriptase inhibitors
}

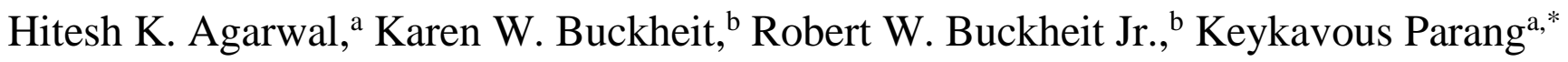 \\ ${ }^{a}$ Department of Biomedical and Pharmaceutical Sciences, College of Pharmacy, University of Rhode Island, Kingston, RI \\ 02881, USA
}

${ }^{b}$ ImQuest BioSciences Inc. 7340 Executive Way, Suite R, Frederick, MD, 21704, USA

This is where the receipt/accepted dates will go; Received Month XX, 2000; Accepted Month XX, 2000 [BMCL RECEIPT]

\begin{abstract}
Three nucleoside analogues, 3'-fluoro-2',3'-dideoxythymidine (FLT), 3'-azido-2',3'-dideoxythymidine (AZT), and 2',3'dideoxy-3'-thiacytidine (3TC) were conjugated with three different dicarboxylic acids to afford the long chain dicarboxylate esters of nucleosides. In general, dinucleoside ester conjugates of FLT and 3TC with long chain dicarboxylic acids exhibited higher anti-HIV activity than their parent nucleosides. Dodecanoate and tetradecanoate dinucleoside ester derivatives of FLT were found to be the most potent compounds with $\mathrm{EC}_{50}$ values of $0.8-1.0 \mathrm{nM}$ and 3-4 $\mathrm{nM}$ against HIV-1 US/92/727 and HIV-1 ${ }_{\text {IIIB }}$ cells, respectively. The anti-HIV activity of the 3TC conjugates containing long chain dicarboxylate diester $\left(\mathrm{EC}_{50}=3-60 \mathrm{nM}\right)$ was improved by $1.5-66$ fold when compared to 3TC $\left(\mathrm{EC}_{50}=90-200 \mathrm{nM}\right)$. This study reveals that the symmetrical ester conjugation of dicarboxylic acids with a number of nucleosides results in conjugates with improved anti-HIV profile.
\end{abstract}

Nucleoside reverse transcriptase inhibitors (NRTIs) are commonly used for the treatment of human immunodeficiency virus (HIV) infection. NRTIs exert their pharmacological effects after intracellular phosphorylation to monophosphates, diphosphates, and triphosphates in the presence of the host cellular kinases. Nucleoside triphosphates inhibit the reverse transcriptase, a crucial enzyme for HIV life cycle, through substrate competition with natural deoxynucleosides and incorporation into the viral DNA that leads to the chain termination. ${ }^{1,2}$ Some examples of commercially available NRTIs are 2',3'-dideoxy-3'thiacytidine (3TC), 2', 3'-didehydro-2',3'dideoxythymidine (d4T), 2',3'-dideoxy-5-fluoro-3'thiacytidine (FTC), 2',3'-dideoxycytidine (ddC), 3'azido-3'-deoxythymidine (AZT), and (R)-9-(2phosphonomethoxypropyl)adenine (TFV). In spite of the potent anti-HIV activities, NRTIs face major challenges such as high levels of clinical toxicity including bone marrow suppression and neuropathy, drug resistance, low therapeutic index, and/or mitochondrial toxicity..$^{3-6}$ Combination therapy in Highly Active Antiretroviral Therapy (HAART) programs using different classes of anti-HIV drugs provides several potential advantages, such as reducing the drug resistance and controling HIV-1 infection. ${ }^{7}$

Despite the success of HAART, the hydrophilic nature of NRTIs leads to limited cellular uptake and bioavailability. Various nucleoside prodrugs have been synthesized in the past to overcome these short comings. ${ }^{3,8} \mathrm{We}$ have previously reported the synthesis of lipophilic fatty acyl esters of anti-HIV nucleosides; AZT, 3'-fluoro-2',3'-dideoxythymidine (FLT), 3TC, and d4T. ${ }^{9-13}$ Lipophilic fatty acyl esters of anti-HIV nucleosides demonstrated higher anti-HIV activity compared to the parent nucleosides. ${ }^{10,14}$ Cellular uptake studies indicated that the long chain fatty acyl esters of 3TC had improved cellular uptake due to improved lipophilicity and were able to hydrolyze to parent nucleoside intracellularly. ${ }^{14}$

Herein, we report the synthesis of long chain dicarboxylic acid esters of FLT, AZT and 3TC to determine whether the presence of two nucleosides on fatty acyl chains will affect the overall anti-HIV activity. Three long dicarboxylic acids with chain lengths of $\mathrm{C} 10$ (sebacic acid), C12 (dodecandioic acid), and $\mathrm{C} 14$ (tetradecandioic acid) were selected for the conjugation. The conjugates were expected to have high lipophilic nature because of the presence of long chain dicarboxylate esters and thereby to have improved cellular uptake properties. We have previously shown the lipophilic nature and/or higher cellular uptake of the fatty acyl esters of the nucleosides compared to the their parent nucleosides. ${ }^{9,10,14}$ Furthermore, the conjugation of anti-HIV nucleosides with three long chain dicarboxylic acids will provide insights about the structure-activity relationships of these conjugates. Once the ester enters the cells, it is expected to release two parent nucleosides after intracellular ester hydrolysis as shown previously with fatty acyl ester conjugates of 3TC. ${ }^{14}$ The results of this study demonstrate that conjugation of two similar nucleosides with dicarboxylic fatty acids yields antiHIV agents having enhanced lipophilicity and increased potency. These conjugates were envisioned and designed to be used as topical anti-HIV microbicides, which are topically applied agents that prevent or reduce transmission of HIV/AIDS.

Symmetrical long chain fatty acyl dicarboxylate esters of FLT-FLT, AZT-AZT, and 3TC-3TC were synthesized. Scheme 1 depicts the general synthesis of 
dinucleoside dicarboxylate ester derivatives of FLTFLT (6-8) and AZT-AZT (9-11). The compounds were synthesized by reaction of commercially available nucleosides with three different dicarboxylic acids (sebacic acid, dodecandioic acid, and tetradecandioic acid) in the presence of 1,1,3,3-tetramethyluronium hexafluorophosphate (HBTU) as coupling reagent and $\mathrm{N}, \mathrm{N}$-diisopropylethylamine (DIPEA) as the base (Scheme 1) in DMF at room temperature. The final products were purified by using a reversed phase HPLC.

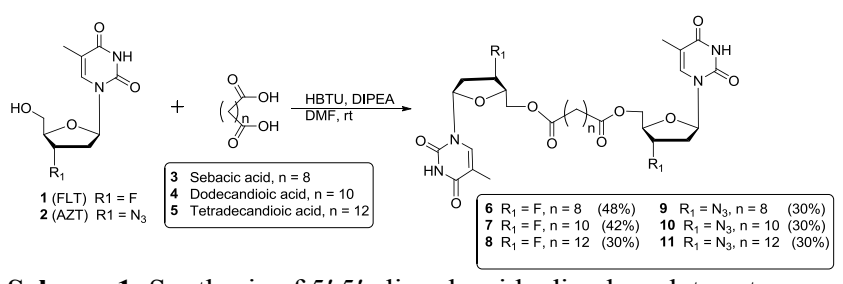

Scheme 1. Synthesis of 5',5'-dinucleoside dicarboxylate ester derivatives of FLT (6-8) and AZT (9-11)

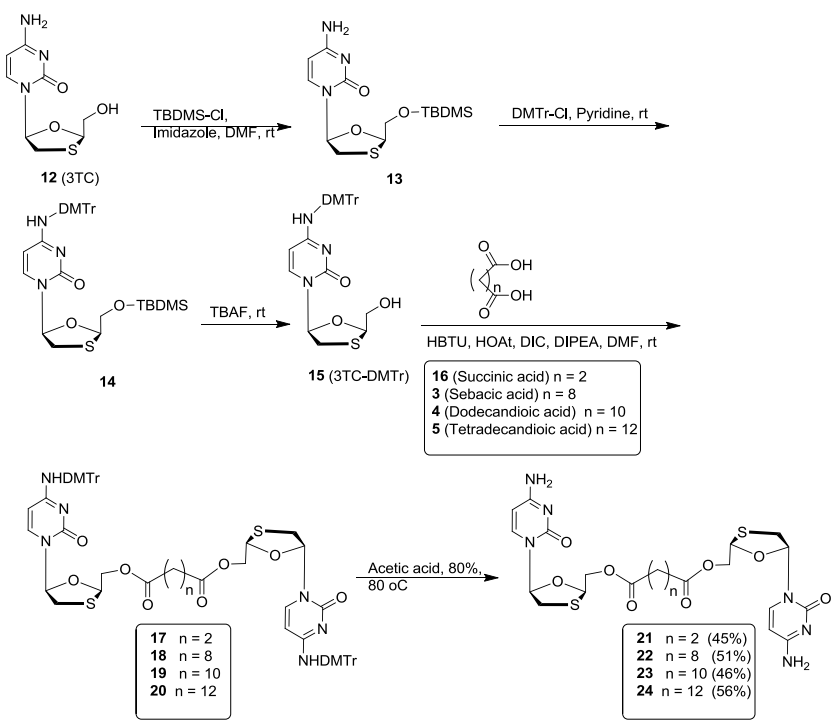

Scheme 2. Synthesis of symmetrical 5',5'-dinucleoside dicarboxylate ester derivatives of 3TC (21-24).

The Synthesis of fatty acyl dicarboxylate esters of 3TC is shown in Scheme 2. N4-amino protection of $3 \mathrm{TC}$ was required before conjugation with dicarboxylic acids. First, tert-butyldimethylsilyl chloride (TBDMS$\mathrm{Cl}$ ) was reacted with $3 \mathrm{TC}$ in the presence of imidazole to afford 5'-O-TBDMS-3TC. Then N4-amino group of 5'-O-TBDMS-3TC was further protected with 4,4'dimethoxytrityl (DMTr) protecting group by reaction with $\mathrm{DMTr}-\mathrm{Cl}$ in the presence of pyridine. Finally, TBDMS was removed by using tetrabutylammonium fluoride (TBAF) to yield $\mathrm{N}_{4}-\mathrm{DMTr}-3 \mathrm{TC}$ according to the previously reported procedure by us. ${ }^{15}$ The esterification was carried out with four different dicarboxylic acids (e.g., succinic acid, sebacic acid, dodecandioic acid, and tetradecandioic acid) in the presence of HBTU and DIPEA to afford $\mathrm{N}_{4}-\mathrm{DMTr}$ protected dinucleoside dicarboxylate esters (17-20) as crude products that were isolated by using extraction.
The DMTr group was deprotected by heating the reaction mixture in $80 \%$ acetic acid in water $(\mathrm{v} / \mathrm{v})$ at 80 ${ }^{\circ} \mathrm{C}$ to give di-3TC-dicarboxylate esters (21-24) (Scheme 2).

The chemical structures of the final products were characterized by nuclear magnetic resonance spectrometry ( ${ }^{1} \mathrm{H}$ NMR and ${ }^{13} \mathrm{C}$ NMR), and were confirmed by a high-resolution PE Biosystems Mariner API time-of-flight electrospray mass spectrometer. The purity of the final products $(>95 \%)$ was confirmed by using a Hitachi analytical HPLC system on a C18 column using a gradient system (water:acetonitrile 30:70 $\mathrm{v} / \mathrm{v}$ ) at constant flow rate of $1 \mathrm{~mL} / \mathrm{min}$ with $\mathrm{UV}$ detection at $265 \mathrm{~nm}$.

Synthesized dinucleoside ester conjugates were evaluated for their ability to inhibit HIV-1 (subtype B, US/92/727) and (subtype IIIB) replication in human PBMC and CEM-SS cells, respectively. ${ }^{16,17}$ Table 1 illustrates the anti-HIV-1 activity $\left(\mathrm{EC}_{50}\right)$ and cytotoxicity $\left(\mathrm{TC}_{50}\right)$ of the synthesized compounds compared with their corresponding parent nucleosides. No cytotoxicity was observed up to the highest tested concentration $\left(\mathrm{TC}_{50}>1000 \mathrm{nM}\right)$ for the synthesized conjugates.

The anti-HIV activity of the 3TC conjugates containing long chain dicarboxylate $\mathbf{( 2 2 - 2 4}, \mathrm{EC}_{50}=3-$ $60 \mathrm{nM}$ ) was improved by 1.5-66 fold when compared to $3 \mathrm{TC}\left(\mathrm{EC}_{50}=90-200 \mathrm{nM}\right)$. The 3TC ester of tetradecandicarboxylic acid $\left(\mathbf{2 4}, \mathrm{EC}_{50}=3-30 \mathrm{nM}\right)$ showed 3-66 times enhanced anti-HIV activity in comparison to 3TC. Dodecandicarboxylate ester of 3TC $\left(\mathbf{2 3}, \mathrm{EC}_{50}=9-20 \mathrm{nM}\right)$ exhibited 4.5-22-fold higher anti-HIV activity than 3TC. The activity of decanoate ester of 3TC (22) was 1.5-6.6 times higher than 3TC. However, succinate ester of $3 \mathrm{TC}\left(7, \mathrm{EC}_{50}=130-150\right.$ $\mathrm{nM})$ had comparable anti-HIV activity with $3 \mathrm{TC}\left(\mathrm{EC}_{50}\right.$ $=90-200 \mathrm{nM})$. These data indicate that the anti-HIV activity of dicarboxylate ester conjugates of dinucleosides depends on the chain length of the spacer between two nucleosides. The optimal antiviral activity for 3TC conjugates was obtained with dodecandioic and tetradecandioic ester conjugates.

In general, dinucleoside ester conjugates of FLT (68) and 3TC (22-24) with long chain dicarboxylic acids exhibited higher anti-HIV activity than their parent nucleosides. On the other hand, the AZT conjugates (911, $\mathrm{EC}_{50}=2-5 \mathrm{nM}$ ) showed comparable activity with AZT $\left(\mathrm{EC}_{50}=2-8 \mathrm{nM}\right)$ against HIV in both PBMC and CEM-SS assays.

The dicarboxylic esters of FLT $\left(\mathbf{6}-\mathbf{8}, \mathrm{EC}_{50}=0.76-1\right.$ $\mathrm{nM}$ ) exhibited slightly higher anti-HIV activity than their parent nucleoside FLT in PBMC assay against HIV-1 $1_{\text {US/92/727. Among all the conjugates, FLT esters } 7}$ and $\mathbf{8}$ were the most potent conjugates against HIV in the series with $\mathrm{EC}_{50}$ values of 0.97 and $0.76 \mathrm{nM}$, respectively, that was approximately 2 times higher than that of FLT $\left(\mathrm{EC}_{50}=2 \mathrm{nM}\right)$. The anti-HIV activity of FLT conjugates $\left(\mathbf{6}-\mathbf{8}, \mathrm{EC}_{50}=3-4 \mathrm{nM}\right)$ in CEM-SS's against $\mathrm{HIV}-1_{\text {III-B }}$ was found to be 5-6.6 times higher 
Table 1. Anti-HIV activity of dicarboxylic acid esters of dinucleoside conjugates.

\begin{tabular}{|c|c|c|c|c|c|c|c|c|}
\hline \multirow[b]{2}{*}{ Compd } & \multirow[b]{2}{*}{ Chemical Name } & \multicolumn{3}{|c|}{ PBMC/HIV-1 $1_{\text {US/92/727 }}$} & \multicolumn{3}{|c|}{ CEM-SS/HIV-1 IIIB $_{\text {I }}$} & \multirow{2}{*}{$\begin{array}{l}\log P \\
(\text { Calcd })^{d}\end{array}$} \\
\hline & & $\begin{array}{l}\mathbf{E C}_{50} \\
(\mathbf{n M})^{\mathrm{a}}\end{array}$ & $\begin{array}{l}\mathbf{T C}_{50} \\
(\mathbf{n M})^{\mathbf{b}}\end{array}$ & $\mathbf{T I}^{\mathrm{c}}$ & $\mathbf{E C}_{50}(\mathrm{nM})^{\mathrm{a}}$ & $\begin{array}{l}\mathbf{T C}_{50} \\
(\mathbf{n M})^{\mathbf{b}}\end{array}$ & $\mathbf{T I}^{\mathrm{c}}$ & \\
\hline 1 (FLT) & 3'-fluoro-2',3'-deoxythymidine & 2.0 & $>500$ & $>250$ & 20.0 & $>500$ & $>25$ & -0.41 \\
\hline $2(\mathrm{AZT})$ & 3'-azido-2',3'-dideoxythymidine & 8.0 & $>1000$ & $>125$ & 2.0 & $>500$ & $>250$ & $\mathrm{ND}^{\mathrm{e}}$ \\
\hline $12(3 \mathrm{TC})$ & (-)-2',3'-dideoxy-3'-thiacytidine & 90.0 & $>500$ & $>5.6$ & 200.0 & $>500$ & $>2.5$ & 0.06 \\
\hline 6 & 1,10-di-FLT-decanoate & 1.0 & $>1000$ & $>1000$ & 4.0 & $>1000$ & $>250$ & 2.12 \\
\hline 7 & 1,12-di-FLT-dodecanoate & 0.97 & $>1000$ & $>1031$ & 4.0 & $>1000$ & $>250$ & 2.96 \\
\hline 8 & 1,14-di-FLT-tetradecanoate & 0.76 & $>1000$ & $>1316$ & 3.0 & $>1000$ & $>333$ & 3.79 \\
\hline 9 & 1,10-di-AZT-decanoate & 4.0 & $>1000$ & $>250$ & 5.0 & $>1000$ & $>200$ & ND \\
\hline 10 & 1,12-di- AZT-dodecanoate & 2.0 & $>1000$ & $>500$ & 4.0 & $>1000$ & $>250$ & ND \\
\hline 11 & 1,14-di-AZT-tetradecanoate & 3.0 & $>1000$ & $>333$ & 3.0 & $>1000$ & $>333$ & ND \\
\hline 21 & 1,4-di-3TC-succinate & 150.0 & $>1000$ & $>7$ & 130.0 & $>1000$ & $>7.7$ & 0.56 \\
\hline 22 & 1,10-di-3TC-decanoate & 60.0 & $>1000$ & $>17$ & 30.0 & $>1000$ & $>33$ & 3.06 \\
\hline 23 & 1,12-di-3TC-dodecanoate & 20.0 & $>1000$ & $>50$ & 9.0 & $>1000$ & $>333$ & 3.90 \\
\hline 24 & 1,14-di-3TC-tetradecanoate & 30.0 & $>1000$ & $>33$ & 3.0 & $>1000$ & $>333$ & 4.73 \\
\hline
\end{tabular}

${ }^{\mathrm{a}} \mathrm{EC}_{50}\left(50 \%\right.$ effective concentration), All the assays were carried out in triplicate $(\mathrm{n}=3) ;{ }^{\mathrm{b}} \mathrm{TC}_{50}(50 \%$ toxic concentration), All the assays were carried out in triplicate $(\mathrm{n}=3)$; ${ }^{\mathrm{C}}$ Therapeutic index $\left(\mathrm{TC}_{50} / \mathrm{EC}_{50}\right)$; ${ }^{\mathrm{d}}$ Calculated partition coefficient using ChemBioDraw Ultra 12.0; ${ }^{\mathrm{e} N o t}$ determined.

than FLT $\left(\mathrm{EC}_{50}=20 \mathrm{nM}\right)$. The attachment of the long chain dicarboxylic acid analogues to 1 and $\mathbf{1 2}$ enhanced their lipophilicity as shown by calculated partition coefficients (Log P) (Table 1). There was a correlation between lipophilicity and anti-HIV activity of the compounds since more lipophilic compounds exhibited higher anti-HIV activity compared to polar parent nucleoside analogues. As shown previously with other fatty acyl derivatives of nucleosides, ${ }^{14}$ the highly lipophilic conjugates could have higher cellular uptake that contributed to their improved anti-HIV activity.

The anti-HIV activity of 1 (FLT, $\mathrm{EC}_{50}=2 \mathrm{nM}$ ) in PBMC's against HIV-1 $1_{\mathrm{US} / 92 / 727}$ was found to be 4 and 45 times higher than 2 (AZT, $\left.\mathrm{EC}_{50}=8 \mathrm{nM}\right)$ and $\mathbf{1 2}$ $\left(3 \mathrm{TC}, \mathrm{EC}_{50}=45 \mathrm{nM}\right)$, respectively. Similarly, the FLT esters of long chain dicarboxylic acids (6-8, $\mathrm{EC}_{50}=$ $0.76-1.0 \mathrm{nM}$ ) were more potent than the corresponding AZT conjugates $\left(\mathbf{9 - 1 1}, \mathrm{EC}_{50}=2.0-4.0 \mathrm{nM}\right)$ and $3 \mathrm{TC}$ conjugates $\left(\mathbf{2 2 - 2 4}, \mathrm{EC}_{50}=20-60 \mathrm{nM}\right)$.

A number of symmetrical $5^{\prime}-O$-substituted dicarboxylate ester derivatives of NRTIs were synthesized, and their anti-HIV activity was evaluated. In general, the conjugation of selected long chain dicarboxylic acids NRTIs resulted in better anti-HIV profiles than the corresponding parent nucleosides.
Among all the dinucleoside diester derivatives, FLT-FLT conjugates $\mathbf{7}$ and $\mathbf{8}$ were found to have better anti-HIV activity than $\mathbf{1}$ and the other dicarboxylate dinucleoside derivatives. The data indicate that conjugation of the NRTIs with dicarboxylic acids is an effective strategy in achieving higher anti-HIV activity possibly by improving the lipophilicity and potentially cellular uptake of the parent nucleosides. These data provide the basis for rational optimization of NRTIs through conjugation of two nucleosides with long chain dicarboxylic acids.

\section{Acknowledgements}

We acknowledge the National Science Foundation, Grant Number CHE 0748555 for the financial support and National Center for Research Resources, NIH, and Grant Number 1 P20 RR16457 for sponsoring the core facility. The authors wish to acknowledge the technical contribution of Dr. Lu Yang and Ms. Ashlee Boczar for the antiviral assays described herein.

\section{Supplementary data}

Supplementary data (experimental synthetic procedures and characterization of compounds using ${ }^{1} \mathrm{H}$ 
NMR, ${ }^{13} \mathrm{C}$ NMR, and HR-MS (ESI-TOF), and antiHIV assays) can be found in the online version of this article.

\section{References and notes}

1. Lee, K.; Chu, C. K. Antimicrob. Agents Chemother., 2001, 45, 138.

2. Nikolenko, G. N.; Palmer, S.; Maldarelli, M.; Mellors, J. W.; Coffin, J. M.; Pathak, V. K. Proc. Natl. Acad. Sci. U. S. A. 2005, 102, 2093.

3. Tan, X.; Chu, C. K.; Boudinot, F. D. Advanced Drug Delivery Reviews 1999, 39, 117.

4. Lewis, W.; Kohlera, J. J.; Hosseinia, S. H.; Haasea, C. P.; Copelandb, W. C.; Bienstockb, R. J.; Ludawaya, T.; McNaughta, J.; Russa, R.; Stuarta, T.; Santoiannia, R. AIDS 2006, 20, 675.

5. Lund, K. C.; Peterson, L. L.; Wallace, K. B. Antimicrob. Agents Chemother. 2007, 51, 2531.

6. Wendelsdorf K. V.; Song, Z.; Cao, Y.; Samuels, D. C. PLoS Comput. Biol. 2009, 5(1):e1000261.

7. Zdanowicz, M. M. Am. J. Pharm. Educ. 2006, 70, 100.

8. Li, F.; Maag, H.; Aldredson, T. J. Pharma. Sci. 2008, 97, 1109.

9. Agarwal, H. K.; Chhikara, B. S.; Doncel, G. F.; Parang. K. J. Med. Chem. 2012, 55, 2672.
10. Agarwal, H. K.; Loethan, K.; Mandal, D.; Gustavo, D. F.; Parang, K. Bioorg. Med. Chem. Lett. 2011, 7, 1917.

11.Parang, K.; Knaus, E. E.; Wiebe, L. I. Nucleosides \& Nucleotides 1998, 17, 987.

12.Parang, K.; Knaus, E. E.; Wiebe, L. I. Antiviral. Chem. Chemother. 1998, 9, 311.

13.Doncel, G. F.; Parang, K.; Agarwal, H. K. PCT Int. Appl. (2009), 96pp. CODEN: PIXXD2 WO 2009009625 A2 20090115 Application: WO 2008US69571 20080709.

14. Agarwal, H. K.; Hanley, M.; Ye, G.; Chhikara, B. S.; Ye, G.; Doncel, G. F.; Parang, K. J. Med. Chem. 2012, 55, 4861.

15.Chimalakonda, K. C.; Agarwal, H. K.; Kumar, A.; Parang, K.; Mehvar, R. Bioconjug. Chem. 2007, 18, 2097.

16. Watson, K. M.; Buckheit, C. E.; Buckheit, R. W., Jr. Antimicrob Agents Chemother. 2008, 52, 2787.

17. Buckheit R. W. Jr; Kinjerski, T. L.; Fliakas-Boltz, V.; Russell, J. D.; Stup, T. L.; Pallansch, L. A.; Brouwer, W. G.; Dao, D. C.; Harrison, W. A.; Schultz, R. J.; Bader, J. P.; Yang, S. S. Antimicrob. Agents Chemother. 1995, 39, 2718. 